УДК 630*524.634: 630*561.26: 519.876

\title{
ФАКТОРНЫЙ АНАЛИЗ ПОКАЗАТЕЛЕЙ КРИВЫХ ВЫСОТ ДЕНДРОРЯДОВ РАЗНОВОЗРАСТНОГО СОСНЯКА СИБИРИ () 2015
}

П.М. Мазуркин, доктор технических наук, профессор, заведующий кафедрой природообустройства, академик РАЕ и РАЕН, член Европейской Академии Естествознания ФГБОУ «Поволжский государственный технологический университет», Йошкар-Ола (Россия), kaf_po@mail.ru

Введение. Применительно к множеству из 203 модельных и 16 сухостойных ангарских сосен $[1,2]$ при выявлении математических связей между 24 измеренными показателями ствола деревьев применяли следующие основные научно-методологические принципы:

1) коррелятивная вариация по Ч. Дарвину [1];

2) дополнительность разновременных измерений в геоботанике [2];

3) закон Барри Коммонера в экологии «Всё связано со всем» [18];

4) эвристические закономерности в фитоценологии [3, 17];

5) биотехнический закон для идентификации закономерностей [4-16].

По принципу дополнительности из данных измерений 1963 г., полученных экспедицией проф. П.М. Верхунова, для кривых высот были выбраны 11 показателей (табл. 1). Они полно характеризуют лесной фитоценоз в его основной части - древостое по стволам. Это даст в последующем проводить анализ крон и расположения деревьев.

Цель статьи - в продолжение статей $[6,8,9]$ показать методику факторного анализа таксационных показателей [12-15] трендами у новых элементов древостоя в виде дендрометрических рядов (дендрорядов) на примере кривых высот ангарских сосен.

Исходные данные. Кривая высот [13] для 219 ангарских сосен дается биотехническим законом

$$
H_{c}=a_{1} D_{1.3}^{\kappa} a_{2} \exp \left(-a_{3} D_{1.3}^{\kappa}{ }^{a_{4}}\right),
$$

где: $H_{c}$ - высота ствола, м; $D_{1,3}^{\kappa}$ - диаметр ствола на высоте 1,3 м в коре (для сухостоя без коры), см $a_{1}$ - напряженность роста ангарских сосен в высоту, м; $a_{2}$ - интенсивность роста ствола; $a_{3}$ - активность спада высоты; $a_{4}$ - интенсивность спада высоты.

Bсе 11 показателей образуют полное множество параметров, характеризующих изучаемую систему в виде пробной площади сосняка. Каждый дендроряд содержит $N$ сосен. Граничные условия кривых высот в дендрорядах сосен определяются минимальными $D_{\min }, H_{\min }$ и максимальными $D_{\max }, H_{\max }$ диаметрами и высотами. Размах между фактическими толщинами $\Delta D=D_{\max }-D_{\min }$ и высотами $\Delta H=H_{\max }-H_{\min }$ определяет результат поведения древостоя за время жизни самой старой сосны в 464 года [12]. По существующей доктрине среднего дерева для сравнения учли также среднеарифметиче- 
ские значения $\bar{D}$ и $\bar{H}$. По формуле (1) прямыми расчетами в Excel вычислили оптимальные значения $D^{*}$ и $H^{*}$.

Таблица 1

Структурные параметры дендрорядов сосняка на пробной площади по кривым высот

\begin{tabular}{|c|c|c|c|c|c|c|c|c|c|c|c|c|}
\hline \multirow{2}{*}{$\begin{array}{c}\text { № } \\
\text { ряда }\end{array}$} & \multirow{2}{*}{$\begin{array}{c}\text { Дендрометрический } \\
\text { ряд сосен }\end{array}$} & \multirow{2}{*}{$\begin{array}{l}N, \\
\text { шт. }\end{array}$} & \multicolumn{5}{|c|}{ Параметры толщины, см } & \multicolumn{5}{|c|}{ Параметры высоты, м } \\
\hline & & & $D_{\min }$ & $D_{\max }$ & $\Delta D$ & $\bar{D}$ & $D^{*}$ & $H_{\text {min }}$ & $H_{\text {max }}$ & $\Delta H$ & $\bar{H}$ & $H^{*}$ \\
\hline 1 & сверхлидеры & 6 & 25.8 & 66.2 & 40.4 & 42.97 & 166 & 27.4 & 32.5 & 5.1 & 29.62 & 38.1 \\
\hline 2 & сильнейшие & 4 & 22.2 & 52.6 & 30.4 & 34.25 & 67 & 23.3 & 30.5 & 7.2 & 26.75 & 31.0 \\
\hline 3 & еень сильные & 4 & 25.4 & 56.0 & 30.6 & 37.10 & 68 & 24.2 & 30.0 & 5.8 & 26.88 & 30.3 \\
\hline 4 & сильные & 6 & 19.8 & 43.6 & 23.8 & 30.00 & 82 & 20.3 & 28.3 & 8.0 & 24.23 & 31.3 \\
\hline 5 & слабонапряженные & 9 & 10.4 & 71.4 & 61.0 & 28.67 & 62 & 12.1 & 29.0 & 16.9 & 20.50 & 29.1 \\
\hline 6 & малонапряженные & 16 & 12.2 & 68.2 & 56.0 & 37.50 & 55 & 10.5 & 28.7 & 18.2 & 22.21 & 28.4 \\
\hline 7 & Напряженные & 9 & 23.4 & 68.6 & 45.2 & 39.89 & 62 & 22.0 & 27.8 & 5.8 & 25.28 & 27.8 \\
\hline 8 & сильнонапряженные & 16 & 19.8 & 68.2 & 48.4 & 37.97 & 66 & 19.5 & 27.6 & 8.1 & 24.74 & 27.8 \\
\hline 9 & высокоинтенсивные & 22 & 13.4 & 63.6 & 50.2 & 24.73 & 52 & 12.0 & 27.0 & 15.0 & 18.66 & 27.0 \\
\hline 10 & супернапряженные & 14 & 22.8 & 41.6 & 18.8 & 31.36 & 329 & 20.0 & 25.2 & 5.2 & 22.53 & 35.9 \\
\hline 11 & начало ослабления & 21 & 19.0 & 64.0 & 45.0 & 32.99 & 100 & 17.2 & 26.8 & 9.6 & 21.81 & 28.0 \\
\hline 12 & сопротивляющиеся & 20 & 14.8 & 60.6 & 45.8 & 31.82 & 69 & 13.0 & 26.5 & 13.5 & 19.63 & 26.6 \\
\hline 13 & слабеющие & 10 & 14.8 & 38.6 & 23.8 & 26.29 & 387 & 12.4 & 23.5 & 11.1 & 18.30 & 44.2 \\
\hline 14 & слабоватые & 28 & 18.0 & 56.6 & 38.6 & 42.08 & 553 & 13.8 & 26.0 & 12.2 & 22.33 & 44.6 \\
\hline 15 & слабые деревья & 9 & 16.4 & 61.2 & 44.8 & 39.18 & 2500 & 12.6 & 26.0 & 13.4 & 19.78 & 198.2 \\
\hline 16 & очень слабые & 4 & 19.8 & 62.8 & 43.0 & 48.60 & 2185 & 13.0 & 24.6 & 11.6 & 21.15 & 178.7 \\
\hline 17 & аутсайдеры & 5 & 31.6 & 66.8 & 35.2 & 46.22 & 63 & 15.4 & 21.9 & 6.5 & 18.56 & 21.4 \\
\hline 18 & усохшие сосны & 16 & 7.2 & 53.8 & 46.6 & 29.93 & 73 & 10.5 & 28.5 & 18.0 & 20.25 & 28.6 \\
\hline
\end{tabular}

Примечание. *Оптимумы по формуле (1) дендрорядов с учетом погрешности измерений.

Чтобы стать в действительности природнылм ресурсом (биоцентристский акцент), нужны исследования связей между параметрами 18 рядов по таблице 1.

Анализ трендами. Для факторного анализа достаточно выявить тенденции (тренды). Это дает совокупность детерминированных биоэнергетических связей между деревьями в древостое, сложившихся к моменту рубки, без учета турбулентных отношений деревьев к соседям и к внешней среде.

Общее уравнение тенденции для всех $11^{2}=121$ имеющихся в таблице 1 факторных отношений имеет вид

$$
y=a_{1} x^{a_{2}} \exp \left(-a_{3} x^{a_{4}}\right)+a_{5} x^{a_{6}} \exp \left(-a_{7} x^{a_{8}}\right)
$$

где $y$ - показатель; $x$ - объясняющая переменная (этот же фактор); $a_{1} \ldots a_{8}$ - параметры (2), получаемые при идентификации в программной среде CurveExpert.

Каждый фактор имеет свой вектор предпорядка предпочтительности типа «лучше $\rightarrow$ хуже». Из 11 факторов два $\left(r_{\Delta D}, r_{\Delta H}\right)$ имеют направленность «если меньше, то лучше», а остальные факторы расположены по вектору «если больше, то лучше». С учетом направленности ранги могут заменить значения фактора. Ранги снимают математическую проблему «проклятия размерности».

В таблице 2 приведены ранги. Затем выполнено суммирование рангов.

Критерий $\bar{R}$ для среднеранговой оценки дендрорядов будет равен

$$
\bar{R}=\frac{1}{m \cdot n} \sum_{i=1}^{m} \sum_{j=1}^{n} r_{i j},
$$

где $m$ - количество рядов, $i$ - номер ряда, $n$ - количество факторов, $j$ - номер. 
Таблица 2

Ранговые распределения значений параметров дендрорядов сосняка по кривым высот

\begin{tabular}{|c|c|c|c|c|c|c|c|c|c|c|c|c|c|}
\hline \multirow{2}{*}{$i$} & $j=1$ & 2 & 3 & 4 & 5 & 6 & 7 & 8 & 9 & 10 & 11 & Сумма & Место \\
\cline { 2 - 15 } & $r_{N}$ & $r_{D \min }$ & $r_{\max }$ & $r_{\Delta D}$ & $r_{\bar{D}}$ & $r_{D^{*}}$ & $r_{H \min }$ & $r_{H \max }$ & $r_{\Delta H}$ & $r_{\bar{H}}$ & $r_{H^{*}}$ & $\sum r$ & $I_{x}$ \\
\hline 1 & 8 & 1 & 4 & 6 & 2 & 5 & 0 & 0 & 5 & 0 & 4 & 35 & 1 \\
\hline 2 & 10 & 5 & 13 & 2 & 9 & 11 & 2 & 3 & 6 & 2 & 7 & 70 & 4 \\
\hline 3 & 10 & 2 & 11 & 3 & 8 & 10 & 1 & 16 & 18 & 1 & 8 & 88 & 9 \\
\hline 4 & 8 & 6 & 14 & 1 & 13 & 7 & 4 & 3 & 7 & 5 & 6 & 74 & 5 \\
\hline 5 & 7 & 13 & 0 & 16 & 15 & 14 & 12 & 15 & 2 & 11 & 9 & 114 & 13 \\
\hline 6 & 4 & 12 & 2 & 15 & 7 & 15 & 14 & 9 & 14 & 8 & 11 & 111 & 12 \\
\hline 7 & 7 & 3 & 1 & 11 & 4 & 14 & 3 & 10 & 12 & 3 & 13 & 81 & 7 \\
\hline 8 & 4 & 6 & 2 & 13 & 6 & 12 & 6 & 13 & 11 & 4 & 13 & 90 & 10 \\
\hline 9 & 1 & 11 & 6 & 14 & 17 & 16 & 13 & 4 & 17 & 15 & 14 & 128 & 17 \\
\hline 10 & 5 & 4 & 15 & 0 & 12 & 4 & 5 & 0 & 5 & 6 & 5 & 61 & 2 \\
\hline 11 & 2 & 7 & 5 & 9 & 10 & 6 & 7 & 3 & 6 & 9 & 12 & 76 & 6 \\
\hline 12 & 3 & 10 & 9 & 10 & 11 & 9 & 10 & 16 & 18 & 14 & 15 & 125 & 16 \\
\hline 13 & 6 & 10 & 16 & 1 & 16 & 3 & 12 & 3 & 7 & 17 & 3 & 94 & 11 \\
\hline 14 & 0 & 8 & 10 & 5 & 3 & 2 & 9 & 15 & 2 & 7 & 2 & 63 & 3 \\
\hline 15 & 7 & 9 & 8 & 8 & 5 & 0 & 11 & 9 & 14 & 13 & 0 & 84 & 8 \\
\hline 16 & 10 & 6 & 7 & 7 & 0 & 1 & 10 & 10 & 12 & 10 & 1 & 74 & 5 \\
\hline 17 & 9 & 0 & 3 & 4 & 1 & 13 & 8 & 13 & 11 & 16 & 16 & 94 & 11 \\
\hline 18 & 4 & 14 & 12 & 12 & 14 & 8 & 14 & 4 & 17 & 12 & 10 & 121 & 15 \\
\hline$\sum r$ & 105 & 127 & 138 & 137 & 153 & 150 & 141 & 146 & 184 & 153 & 149 & 1583 & - \\
\hline$I_{y}$ & 1 & 2 & 4 & 3 & 9 & 8 & 5 & 6 & 10 & 9 & 7 & - & 7,99 \\
\hline
\end{tabular}

Для сосняка Сибири критерий будет равен в среднем 1583 / $(18 \times 11)=7,99$ $\approx 8$. Первое место среди рядов занимают сверхлидеры, а второе - высокоинтенсивные в росте в высоту сосны. На третьем месте находится дендроряд слабеющих сосен. Среди 11 показателей на первом месте оказалась численность сосен в дендрорядах, то есть мощность части популяции ангарских сосен. На втором месте находится минимальная толщина ствола (показатель запаса питательных веществ).

Добротность измерений является важнейшим свойством качества статистической выборки, в нашем случае по данным таблицы 1, и измеряется адекватностью ранговых распределений значений факторов по данным таблицы 2.

Полный факторный анализ. В диагональных клетках таблицы 3 расположены коэффициенты корреляции монарных отношений факторов.

Коэффициент коррелятивной вариации сосняка равен 59,5060/11 $1^{2}=$ 0,4918. Показатель применим для сравнения сосняков и популяций деревьев.

Под выражением «коррелятивная вариация» [1, с.126-128] «... я разумею, что вся организация во время роста и развития внутренне связана, и когда слабые вариации встречаются в какой-нибудь одной части и куммулируются путем естественного отбора, другие части оказываются модифицированными. ... модификации в строении, признаваемые систематиками за весьма важные, могут зависеть исключительно от законов вариации и корреляции ...». Изменчивость (вариабельность по Ч. Дарвину) связана с жизненными условиями, которым вид подвергался в течение нескольких последовательных поколений (в рассматри- 
ваемом сосняке содержится пять поколений [7]). Имеются два фактора: природа организма - наиболее важный из двух, и свойства действующих условий [1, c.118]. По фитоценологии [3, 16] все 11 параметров таблицы 1 относятся к результатам комплексного воздействия генотипа и фенотипа.

Таблица 3

Полный факторный анализ трендами и рейтинг факторов как переменных и показателей

\begin{tabular}{|c|c|c|c|c|c|c|c|c|c|c|c|c|c|}
\hline \multirow{2}{*}{$\begin{array}{l}\text { Влияющие } \\
\text { факторы } x\end{array}$} & \multicolumn{11}{|c|}{ Зависимые факторы (показатели $y$ ) } & \multirow{2}{*}{$\begin{array}{c}\text { Сумма } \\
\Sigma r\end{array}$} & \multirow{2}{*}{$\begin{array}{c}\text { Место } \\
I_{x}\end{array}$} \\
\hline & $N$ & $D_{\min }$ & $D_{\max }$ & $\Delta D$ & $\bar{D}$ & $D^{*}$ & $H_{\text {min }}$ & $H_{\max }$ & $\Delta H$ & $\bar{H}$ & $H *$ & & \\
\hline Число $N$ & 0,9919 & 0,6272 & 0,0747 & 0,3737 & 0,5382 & 0,2786 & 0,4880 & 0,1492 & 0,4993 & 0,3990 & 0,2670 & 4,6868 & 8 \\
\hline Диаметр $D_{\min }$ & 333 & 0 & 0,0067 & 0,5273 & 0,5775 & 0 , & 0,9345 & 0,5640 & 0,9599 & 0,8674 & 0,6088 & 7,1792 & 1 \\
\hline Диаметр $D_{\max }$ & 0,1886 & 0,0241 & 0,9864 & 0,8471 & 0,4856 & 0,2515 & 0,1132 & 0,3082 & 0,2146 & 0,1875 & 0,4291 & 4,0359 & 10 \\
\hline Размах $\Delta D$ & 164 & 0,6584 & 0,8793 & 0,9796 & 0,5794 & 0,0265 & 0,5131 & 0,2236 & 0,6607 & 0,2990 & 0,2606 & 5,3966 & 6 \\
\hline Сред & 63 & 0 & 0,4 & 0,0 & 31 & 0 & 0 & 26 & 0,36 & 53 & 97 & 32 & 7 \\
\hline ум $D *$ & 5 & 0,0 & 0,0 & 0,0 & 594 & 0 , & 0 & 20 & 0,1 & 8 & 77 & 70 & 9 \\
\hline Высота $H_{\min }$ & 6 & 0 & 0 & 0,5483 & 328 & 0 & 0 , & 49 & 0,9 & 376 & 97 & 6,8582 & 3 \\
\hline Высота $H_{\max }$ & 06 & 0,6 & & 0,3927 & 0,4394 & 0,6042 & 0,5455 & 0,9663 & 0,4452 & 0,7673 & 0,5393 & 6,0550 & 4 \\
\hline Размах $\Delta H$ & 5012 & 0,9046 & 0,2 & 0,6708 & 0,3398 & 0,6639 & 0,9123 & 0,5308 & 0,9962 & 0,7103 & 0,6162 & 7,0562 & 2 \\
\hline Средняя $\bar{H}$ & 61 & 0,4882 & 0,0633 & 0,3075 & 0,2958 & 0,2723 & 0,8990 & 0,7620 & 0,6823 & 0,9957 & 0,2717 & 5,5439 & 5 \\
\hline Оптимум $H^{*}$ & 0,2433 & 0,0502 & 0,0401 & 0,0620 & 0,4174 & 0,9903 & 0,2506 & 0,2662 & 0,1453 & 0,2018 & 0,9068 & \begin{tabular}{|l|}
3,5740 \\
\end{tabular} & 11 \\
\hline Сумма $\Sigma r$ & 5,1588 & 5,7696 & 3,1791 & 4,7919 & 5,4584 & 5,4147 & 6,3818 & 5,4298 & 6,0456 & 6,1897 & 5,6866 & 59,5060 & - \\
\hline Место $I_{y}$ & 9 & 4 & 11 & 10 & 6 & 8 & 1 & 7 & 3 & 2 & 5 & - & 0,4918 \\
\hline
\end{tabular}

Примечание. Здесь $r$ - коэффициент корреляции тренда или не волновых закономерностей.

По таблице 3 среди влияющих переменных на первом месте находится диаметр $D_{\min }$, на втором - размах $\Delta H$ высоты, а на третьем - высота $H_{\min }$. Минимальные размеры сосен получают высокую значимость в лесной фитоценологии, которая отличается от классической $[3,17]$, прежде всего, индивидуальным подходом к измерениям каждой особи, т.е. достижениями дендрометрии. По сумме коэффициентов пять параметров толщины имеют 25,7319, а по влияющим параметрам высоты - 29,0653. Тогда получается, что нужно рассматривать не кривые высот, а кривые диаметров [13]. Среди зависимых факторов первое место занимает высота $H_{\min }$ ствола, второе - средняя высота $\bar{H}$ и третье - размах $\Delta H$ высоты по дендрорядам. При этом как показатель значимость высоты в сравнении с толщиной в 29,7335 / 24,6137 = 1,208 раза выше.

Корреляционная матрица сильных бинарных трендов

\begin{tabular}{|c|c|c|c|c|c|c|c|c|c|}
\hline \multirow{2}{*}{$x$} & \multicolumn{7}{|c|}{ Зависимые факторы (показатели $y$ ) } \\
\cline { 2 - 10 } & $D_{\min }$ & $D_{\max }$ & $\Delta D$ & $D^{*}$ & $H_{\min }$ & $H_{\max }$ & $\Delta H$ & $\bar{H}$ & $H^{*}$ \\
\hline$D_{\min }$ & & & & & 0,9345 & & 0,9599 & 0,8674 & \\
\hline$D_{\max }$ & & & 0,8471 & & & & & & \\
\hline$\Delta D$ & & 0,8793 & & & & & & & \\
\hline$D^{*}$ & & & & & & & & & 0,9977 \\
\hline$H_{\min }$ & 0,7831 & & & & & 0,8349 & 0,9383 & 0,9376 & \\
\hline$H_{\max }$ & & & & & & & & 0,7673 & \\
\hline$\Delta H$ & 0,9046 & & & & & & & 0,7103 & \\
\hline $\bar{H}$ & & & & & 0,8990 & 0,7620 & & & \\
\hline$H^{*}$ & & & & 0,9903 & & & & & \\
\hline
\end{tabular}

По существующей классификации из теории корреляционного анализа примем условие отбора уравнений, при котором учитываются только те факторные связи, которые имеют коэффициент корреляции $r \geq 0,7$ (табл. 4).

Из таблицы 4 исключились число дендрорядов и средний диаметр. 
В итоге доктрина «среднего дерева» оказывается неадекватной.

Сильных связей оказалось 16 или 14,55\%. По ним можно составлять варианты математической модели трендового (детерминированного) поведения в прошлом древостоя.

Как методический пример рассмотрим сильнейшие бинарные связи при $r \geq 0,9$ (табл. 5). Остались 7 или $6,36 \%$ из $121-11=110$ формул, которые покажем по убыванию $r$.

Структура $H^{*}=f\left(D^{*}\right)$ является кривой высот по оптимумам, которые получаются из закона (1) у 18 дендрорядов, поэтому она занимает

Таблица 5 Сильнейшие бинарные тренды при $r \geq 0,9$

\begin{tabular}{|c|c|c|c|c|c|c|}
\hline \multirow{2}{*}{$x$} & \multicolumn{5}{|c|}{ Зависимые факторы (показатели $y$ ) } \\
\hline & $D_{\min }$ & $D^{*}$ & $H_{\min }$ & $\Delta H$ & $\bar{H}$ & $H^{*}$ \\
\hline$D_{\min }$ & & & 0,9345 & 0,9599 & & \\
\hline$D^{*}$ & & & & & & 0,9977 \\
\hline$H_{\min }$ & & & & 0,9383 & 0,9376 & \\
\hline$\Delta H$ & 0,9046 & & & & & \\
\hline$H^{*}$ & & 0,9903 & & & & \\
\hline
\end{tabular}
первое место по формуле (рис. 1) двухчленной конструкции вида

$$
H^{*}=16,92066 \exp \left(0,45935 D^{* 0,0026040}+0,0048498 D^{* 1,34133}\right. \text {. }
$$

На этом же рисунке 1 показана конструкция кривой (5) диаметров по соответствующим оптимумам.
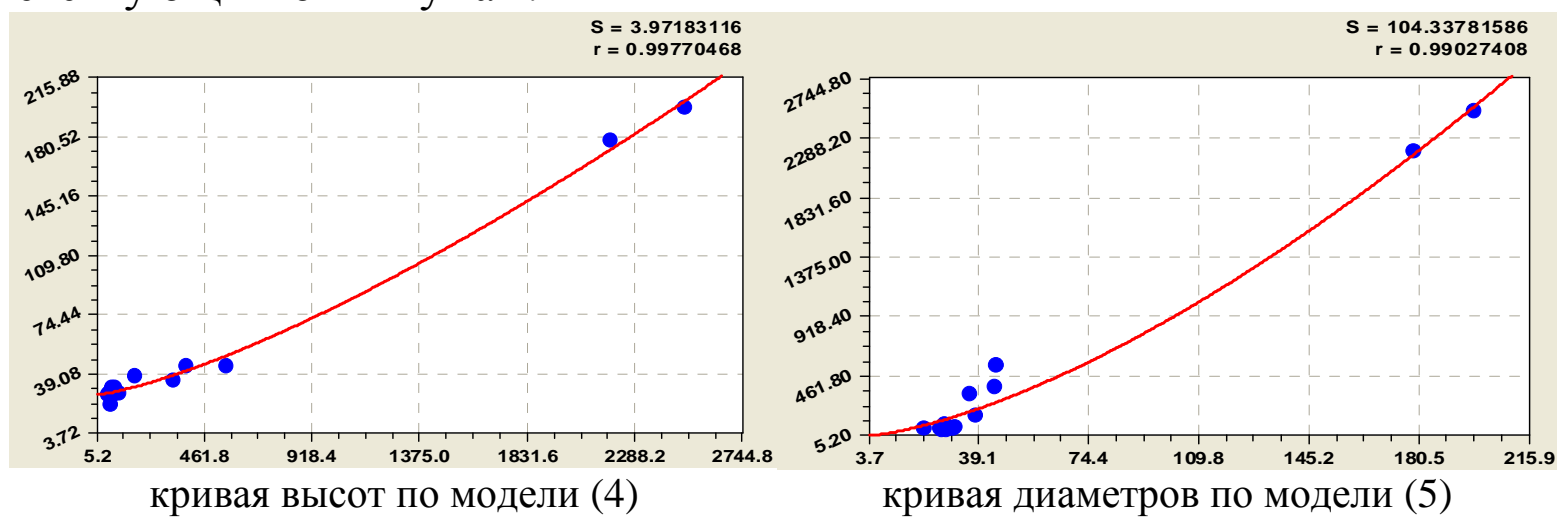

Рис. 1. Кривые оптимумов толщины и высоты по дендрометрическим рядам сосняка Сибири

При этом кривая диаметров получает компактную формулу (рис. 1) вида

$$
D^{*}=0,83968 H^{* 1,51445} \text {. }
$$

Обе закономерности имеют коэффициент корреляции выше 0,99. Но формула (1) проще по конструкции. Поэтому она как тренд предпочтительнее.

Влияния $D_{\min }$ и $H_{\min }$ оказались значимыми (рис. 2) по формулам:

$$
\begin{gathered}
\Delta H=14,88239 \exp \left(0,047735 D_{\min }\right)- \\
-0,011403 D_{\text {min }}^{3,00333} \exp \left(-0,055075 D_{\text {min }}{ }^{1,00830}\right) ; \\
\Delta H=6,99665 \cdot 10^{8} \exp \left(-14,52087 H_{\min }{ }^{0,079438}\right) .
\end{gathered}
$$

Закономерности (6) и (7) являются принципиально новыми. Они показывают, что в древостое естественного происхождения важнейшим показателем становится размах (интервал значений) высоты сосен. На размах $\Delta H$ влияют минимальные толщина и высота, то есть наименьшие особи древостоя как главной части фитоценоза. По закону экспоненциальной гибели (7) с увеличением минимальной высоты, то есть при условии отсутствия крупного подроста 
и нижних ярусов сосняка, размах высоты ствола резко снижается и популяция приближается по своей структуре к однородности. В лесных культурах $\Delta H$ сознательно доводят до нуля и нарушают закон (7).

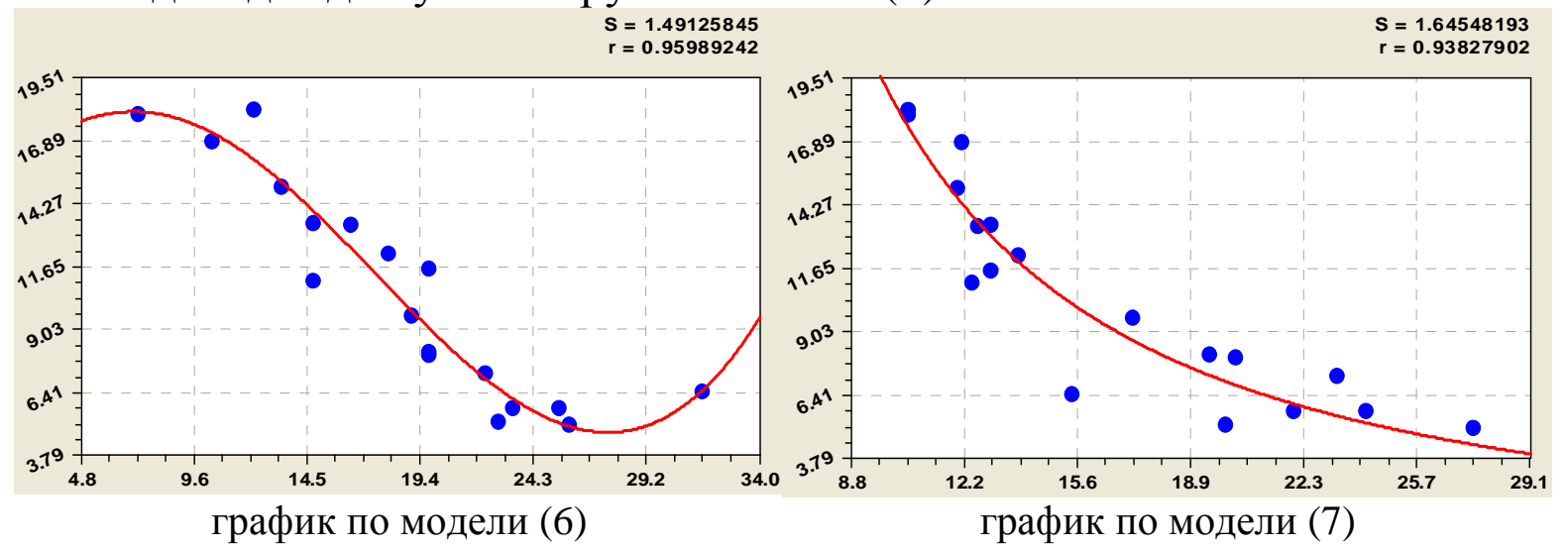

Рис. 2. Изменение размаха высоты ствола модельных ангарских сосен

По закономерности (6) существуют два процесса: во-первых, по закону экспоненциального роста с увеличением толщина нарастет и размах высоты; во-вторых, по закону стрессового возбуждения происходит кризисное изменение показателя. Сложение двух процессов по графику на рисунке 2 дает два экстремума: максимум размаха наблюдается при условии $D_{\min }=7,2$ см, то есть при наличии крупного подроста, а минимум размаха происходит при диаметре 27-28 см у дерева с тонким стволом. Таким образом, вторая составляющая формулы (6) показывает кризис запаса питательных веществ, накапливаемых соснами в нижней части ствола. Если минимальный диаметр ствола станет больше 28 см, то размах высоты $\Delta H$ в сосняке снова начинает нарастать.

Средняя высота древостоя (рис. 3) зависит от минимальной высоты

$$
\bar{H}=7854145,9 \exp \left(-7,34771 H_{\min }{ }^{0,27361}\right)+2,50165 H_{\min }{ }^{0,74557} .
$$

Здесь получается классический оптимум при сумме двух законов - экспоненциальной гибели и показательного роста. При росте подроста (деревья пятого поколения [7]) до высоты 12 м снижает среднюю высоту. Сообщество деревьев «выжидает» развития и роста молодняка. Когда же молодые доросли до 12-13 м, популяция дружно растет дальше, повышая среднюю высоту.

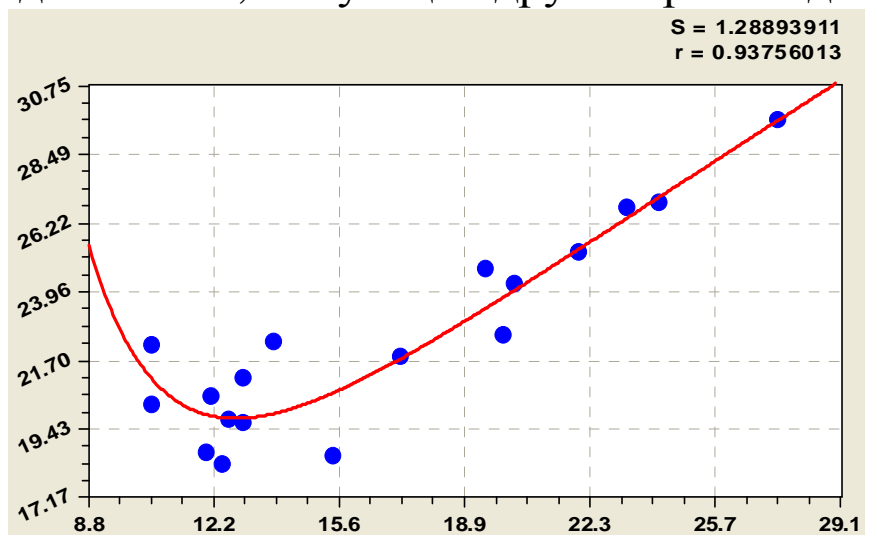

Рис. 3. Изменение средней высоты ствола модельных ангарских сосен

До минимального диаметра в 12-13 см минимальная высота сосны остается почти постоянной и равна около 12 м.

C дальнейшим увеличением $D_{\min }$ до 26 см значение $H_{\min }$ достигает максимума примерно на высоте в 25 м. Затем наступает перелом в поведении и с ростом толщины более 26 см минимальная высота значительно снижается. В результате внутривидовой конкуренции появляются деревья-аутсайдеры.

Кривая высот граничных особей у 18 дендрорядов (рис. 4) имеет вид: 


$$
\begin{gathered}
H_{\min }=11,90922 \exp \left(-0,0037302 D_{\min }\right)+ \\
+2,04028 \cdot 10^{-15} D_{\min }{ }^{12,97745} \exp \left(-0,0027423 D_{\min }{ }^{2,35205}\right) .
\end{gathered}
$$

Как и в любой биологической популяции, повышение размаха фактора, в нашем случае $\Delta H$ (рис. 5), приводит к закону экспоненциальной гибели

$$
D_{\text {min }}=29,32600 \exp \left(-0,0098148 \Delta H^{1,62544}\right) \text {. }
$$

Формула (10) дает ключ к разрешению дискуссий лесоводов о преимуществах одновозрастных (лесные культуры) или разновозрастных древостоев. При условии $\Delta H=0$ для идеального по конструкции сосняка с деревьями одинаковой высоты минимальная толщина будет 29,3 м. С увеличением перепада высот происходит снижение минимальной толщины сосен. При перепаде $\Delta H$ в 18 м $D_{\min }$ равен 9,6 см.

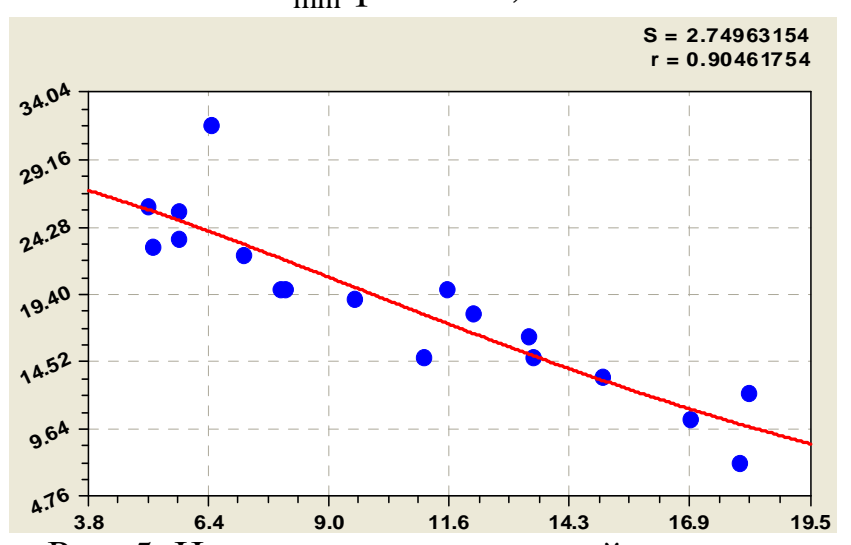
ствола модельных ангарских сосен
Рис. 5. Изменение минимальной толщины

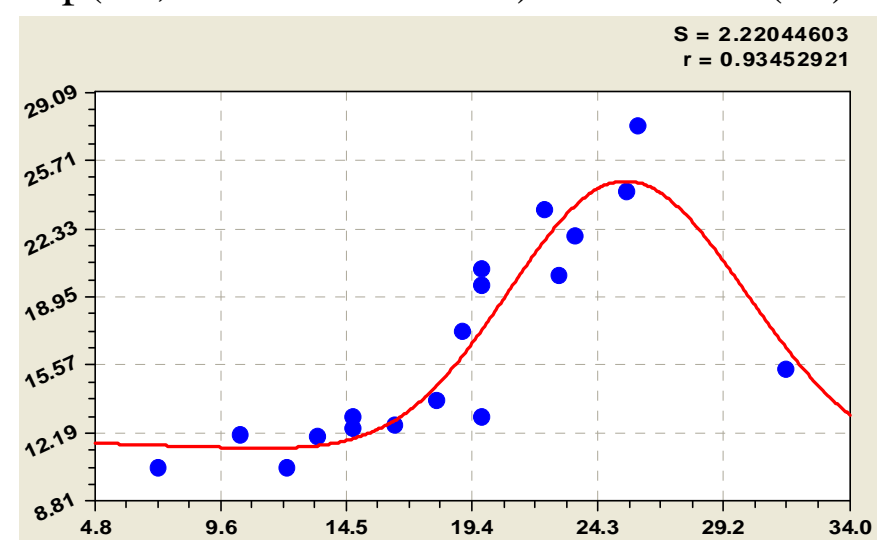

Рис. 4. Кривая высот граничных в дендрорядах модельных ангарских сосен

Любая факторная связь имеет, кроме тренда, еще и волновые уравнения с переменными амплитудой и частотой колебаний. Поэтому даже по тренду можно оценить коэффициент динамичности $k_{\partial}$, вычисляемый (табл. 6) по простой формуле

$$
k_{\partial}=(\hat{y}-y) / y,
$$

где $\hat{y}$ - фактические значения показателя, $y$ - расчетные по выявленной за-

\begin{tabular}{|c|c|c|c|c|c|}
\hline \multirow{2}{*}{$\begin{array}{c}\text { Параметр } \\
\text { дендроряда }\end{array}$} & \multirow{2}{*}{$\begin{array}{l}\text { Коэфф. } \\
\text { коррел. }\end{array}$} & \multicolumn{4}{|c|}{ Динамичность поведения сосен } \\
\hline & & $k_{\partial \max }$ & $r$ & $t$ & название дендроряда \\
\hline Число $N$ & 0,9919 & $-0,1110$ & 8 & & сверхлидеры, сильные \\
\hline Диаметр $D_{\min }$ & 0,9801 & $2699^{\prime}$ & 14 & 18 & ны \\
\hline Диаметр $D_{\max }$ & 9804 & $-0,04$ & 14 & 4 & сил \\
\hline Paзмах $\Delta D$ & 9796 & $-0,0824$ & & 4,13 & сильные, слабеющи \\
\hline Средний $\bar{D}$ & 0,9931 & $-0,0573$ & 17 & 9 & высоко \\
\hline Оптимум $D^{*}$ & 0,9662 & 91,20 & 16 & 9 & высокоинтенсивные \\
\hline Высота $H_{\min }$ & 0,9923 & 0,0841 & 6 & 8 & сильн \\
\hline Высота $H_{\max }$ & {$[0,9663$} & 0,275 & 16 & 3 & очень сильные \\
\hline Paзмax $\Delta H$ & 9962 & 2,0363 & 2 & & слабонапряженные \\
\hline & 957 & $-0,028$ & 6 & 10 & супер \\
\hline Оптимум $H^{*}$ & 9068 & 0,9905 & 15 & 12 & сопротивляющиеся \\
\hline
\end{tabular}
кономерности значения.

Таблица 6 Добротность по коэфДобротность и динамичность параметров сосняка фициенту корреляции ранговых распределений (диагональ в таблице 3) и максимальная динамичность какого-то дендроряда сосняка показаны в таблице 6 .

Наиболее достоверны и добротны значения максимальной высоты с коэффициентом корреляции 0,9663 .

Наименьший коэффициент динамичности 0,0289 
(2,89\%) имеет средняя высота сосен в 10-ом дендроряде супернапряженных в росте в высоту сосен.

Заключение. Анализ развития фитоценологии [17, с. 6-15] показал, что система представлений должна характеризоваться открытостью, стимулирующей ее развитие. В 1985 г. проф. Б.М. Миркин четко отметил свойство старой парадигмы, проявляющееся и поныне в нашей стране [17, с. 7]: «В переходный период старая парадигма выглядит несравненно более обоснованной, а ее представители более респектабельны и авторитетны». За период с XVI века происходил синтез общих представлений о растительном сообществе как об основном объекте фитоценологии [17, с. 9].

Впервые измерительный подход [17, с. 13] в 1987 году ввел проф. Т.А. Работнов по результатам изучения луговой растительности. На этой основе выявление и применение устойчивых законов и закономерностей бинарных отношений между факторами, количественно характеризующих свойства фитоценозов, включая и древостои как основную часть лесных фитоценозов [4-15], позволит развить новое направление в изучении всего растительного покрова статистическую фитоценологию.

Факторный анализ любого древостоя [12], по измерениям стволов у деревьев в растущем состоянии, позволит определить не только наиболее значимые связи, но и осознано управлять структурой и свойствами деревьев с учетом возможных в будущем изменений в древостое как устойчиво развивающемся сообществе растений. Затем появится аналитическая возможность учета и других компонент леса как природной среды.

\section{СПИСОК ЛИТЕРАТУРЫ}

1. Дарвин Ч. Происхождение видов путем естественного отбора. Л.: Наука, $1991.539 \mathrm{c.}$

2. Кучеров И.Б. О принципе дополнительности в геоботанике. Методологические предпосылки возникновения комплементарных подходов к изучению растительности // Журнал общей биологии. 1995. № 4. Том 56. С. 486-505.

3. Лавренко Е.М. Основные закономерности растительных сообществ и пути их изучения // Полевая геоботаника. Том 1. М.-Л.: Изд-во АН СССР, 1959. C.7-263.

4. Мазуркин П.М. Геостатистика сосны // Леса России и хозяйство в них. 2009. № 3. C. 48-54.

5. Мазуркин П.М. Геоэкология: Закономерности современного естествознания. Йошкар-Ола: МарГТУ, 2006. 336 с.

6. Мазуркин П.М. Мазуркин П.М. Дендроряды разновозрастного сосняка по кривым высот // Междисциплинарные исследования в области математического моделирования и информатики / Материалы 4-й научно-практ. internetконф. Отв. ред. Ю.С. Нагорнов. Ульяновск: Изд-во SIMJET, 2014. С. 122-130.

7. Мазуркин П.М. Закономерности разновозрастного сосняка по диаметру стволов для рубок поколений деревьев // ИВУЗ «Лесной журнал». №2. 2012. С. 42-49. 
8. Мазуркин П.М. Ранговые распределения параметров кривых высот по дендрорядам разновозрастного сосняка Сибири // Матер. 5-й научно-практ. internet-конф. «Междисциплинарные исследования в области математического моделирования и информатики» 27-28 января 2015 г. Ульяновск: SIMJET, 2015. C. 92-102.

9. Мазуркин П.М. Структурно-функциональные параметры дендрорядов разновозрастного сосняка Сибири по кривым высот // Матер. 5-й научно-практ. internet-конф. «Междисциплинарные исследования в области математического моделирования и информатики» 27-28 января 2015 г. Ульяновск: SIMJET, 2015. C. 103-112.

10. Мазуркин П.М. Распределение фитомассы сосняка по пробным площадям // Леса России и хозяйство в них. 2009. № 3. С. 22-31.

11. Мазуркин П.М. Устойчивые законы и простые числа // Фундаментальные исследования. 2012. № 3. С. 106-112.

12. Мазуркин П.М. Факторный анализ таксационных показателей // Лесное хозяйство. 2010. № 1. С. 39-40.

13. Мазуркин П.М., Бедертдинов Э.Н., Русинова Н.В. Оценка компонентного неравновесия древостоя по кривым высот и диаметров растущих деревьев // Успехи современного естествознания. 2009. № 8. С. 23-32.

14. Мазуркин П.М., Димитриев А.В. Сосняки заповедника «Присурский»: математический анализ параметров кварталов и выделов леса // Научные тр. ГПЗ «Присурский» (посвящается междунар. году лесов). Т. 26. ЧебоксарыАтрат: КЛИО, 2011. 104 с.

15. Мазуркин П.М., Долгих М.В. Компонентное равновесие и устойчивость древостоя. Йошкар-Ола: МарГТУ, 2011. 164 с.

16. Мазуркин П.М., Филонов А.С. Математическое моделирование. Идентификация однофакторных статистических закономерностей: учеб. пос. Йошкар-Ола: МарГТУ, 2006. 292 с.

17. Миркин Б.М. Теоретические основы современной фитоценологии. М.: Наука, 1985. 137 с.

18. Популярная экология (полезные советы в повседневной жизни) / Гл. ред. Торсуев Н.П. Казань: Изд-во «Экоцентр», 1997. 236 с.

\section{FACTOR ANALYSIS OF CURVES HEIGHTS DENDRO-SERIES MULTIAGE PINE FORESTS OF SIBERIA \\ (C) 2015}

P.M. Mazurkin, Doctor of Technical Sciences, Professor, Academician of the Russian Academy of Natural Sciences and the Russian Academy of Natural Sciences, Member of the European Academy of Natural Sciences,

Volga State Technological University (Yoshkar-Ola), Russia, kaf_po@mail.ru 